The Israeli Journal of Aquaculture - Bamidgeh, IIC:63.2011.609, 6 pages

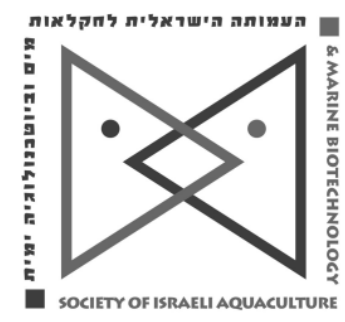

The IJA appears exclusively as a peer-reviewed on-line open access journal at http://www.siamb.org.il

Sale of IJA papers is strictly forbidden.

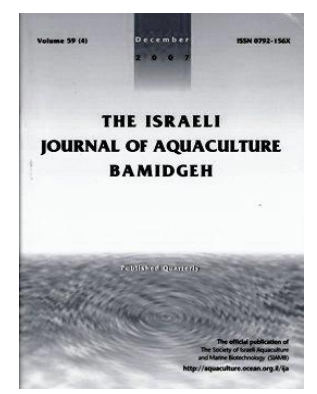

\title{
Effect of Feeding Frequency and One Day Fasting on Tilapia (Oreochromis niloticus) and Water Quality
}

\author{
Morris Villarroel, José Mario R. Alavriño, Javier López-Luna \\ Departamento de Producción Animal, Escuela Técnica Superior de \\ Ingenieros Agrónomos, Universidad Politécnica de Madrid, Ciudad \\ Universitaria, 28040. Madrid, Spain
}

(Received 5.7.10, Accepted 6.9.10)

Key words: Nile tilapia, fasting, water quality, cortisol, recirculation

\begin{abstract}
The aim of this study was to investigate the effects of different feeding frequencies and one day fasting on the quality of tank water in a recirculation system and on the growth, body composition, and welfare of juvenile Nile tilapia (Oreochromis niloticus). One hundred and twenty juveniles ( $24 \pm 4.2 \mathrm{~g}$ ) were fed two or four times a day, with or without a one-day fast every fourth day. Fish that were fed two or four times every day grew more than fish that fasted once a week, but there were no significant differences in food conversion rate or specific growth rate among the four treatments. Regarding body composition, fish fed four times a day, whether fasted or not, had a higher percentage of fat, while the percentage of protein was highest in fish fed four times a day with a one-day fast every fourth day. Plasma cortisol levels at the end of the trial were similar between frequencies, suggesting little effect of feeding frequency on stress level. Electrical conductivity in tank water was highest in the twice a day/fasting group and related to higher sodium $(\mathrm{Na}+)$ and chloride $(\mathrm{Cl}-)$ levels. Overall, results suggest that fasting one day a week does not affect growth efficiency and that tilapia adjust well to relative changes in feeding frequency.
\end{abstract}

* Corresponding author. Tel.: +34-914524869, e-mail: morris.villarroel@upm.es 


\section{Introduction}

Feeding frequency determines the time elapsed between meals (the feeding interval). The effects of feeding interval in fish depend on the species, sex, age, genotype, ability for compensatory growth, and fat deposition. To optimize growth and increase feed efficiency, the feeding interval should be adjusted to favor maximum digestibility and protein deposition. Tilapia fed at 2-3 $\mathrm{h}$ intervals eat more than their stomach volume, so that some feed passes by the stomach without being digested (Riche et al., 2004a). A feeding frequency of one meal every 4-5 hours ( 3 times a day) provides optimum results (Riche et al., 2004b).

Restricted feeding has advantages such as decreased costs, improved feeding efficiency, reduced build-up of fat in the carcass, and improved water quality. Tilapia adapt well to many environments and feeding schedules, including sub-optimum feeding levels. However, feeding tilapia only five days a week (instead of seven) has a negative effect on growth (Byamungu et al., 2001), while increased feeding frequency appears to confer higher resistance to disease (Garcia and Villarroel, 2009). The purpose of our study was to determine the effects of the skip-a-day technique commonly used in poultry (Oyedeji and Atteh, 2005) on the growth of tilapia in recirculation systems, as well as body composition, stress level, and water quality.

\section{Materials and Methods}

The work was carried out in the recirculation aquaculture units at the Field Station of the Agricultural College of the Polytechnic University of Madrid (Spain) in fifteen green 110-I fiberglass tanks $(0.38 \mathrm{~m}$ high, lower diameter $0.54 \mathrm{~m}$, upper diameter $0.65 \mathrm{~m})$. Each tank had one 6-I filter (EHEIM Classic, Mod. 2217, 20 W, $1000 \mathrm{l} / \mathrm{h}$ ), was oxygenated by an air pump (Million Air-MA 200, $4 \mathrm{~W}$ ) with the inlet $20 \mathrm{~cm}$ from the bottom of the tank, and was heated (Atman N2867, $50-60 \mathrm{~Hz}, 20-34^{\circ} \mathrm{C}, 150 \mathrm{~W}$ ) to $26^{\circ} \mathrm{C}$. The water flow rate per tank was $160-180 \mathrm{l} / \mathrm{h}$. Tanks were covered with a $1-\mathrm{cm}$ thick plastic lid $(75 \times 75 \mathrm{~cm})$ to prevent fish jumping out of the tank and decrease evaporative loss. The photoperiod was controlled automatically to be $12 \mathrm{~L}: 12 \mathrm{D}$.

We used 120 male tilapia (Oreochromis niloticus) with an average initial weight of $24 \pm 4.2 \mathrm{~g}$. The tilapia were purchased from a breeding population of genetically male tilapia (GMTß) from Valenciana de Acuicultura (Puçol, Valencia). The experimental fish originated from a single tank within a larger recirculation unit and were handled and fed (twice a day) in a similar manner for two weeks. After that, fish were individually weighed and distributed into twelve tanks at 10 fish per tank (average stocking density $2.2 \pm 0.3 \mathrm{~kg} / \mathrm{m}^{3}$ ). The remaining three tanks were kept as water controls, with no fish or feed added. Fish were randomly assigned to one of four treatments based on feeding frequency, with three tanks and three biofilters per treatment. In treatment 1 , fish were fed twice a day $(08: 00,20: 00)$, every day of the week. In treatment 2, fish were fed four times a day $(08: 00,12: 00,16: 00,20: 00)$, every day of the week. In treatment 3, fish were fed as in treatment 1 (twice a day) for three days and fasted for one day. Finally, in treatment 4, fish were fed as in treatment 2 (four times a day) for three days and fasted for one day.

The tilapia were fed a commercial diet for cyprinids (floating pellets) provided by Dibaq that contained $31 \%$ crude protein, $6 \%$ fat, and $2.5 \%$ fiber. Fish were fed at $8 \%$ of their live weight using programmable feeders (EHEIM 3581, one per tank). We assumed that all provided feed was consumed by the fish since no pellets were observed to accumulate on the surface or the bottom of the tanks. Specific growth rate was calculated as SGR $=100\left(\ln W_{2}-\ln W_{1}\right) /\left(T_{2}-T_{1}\right)$, where $W_{2}=$ final weight of fish, $W_{1}=$ initial weight of fish, and $T_{1}$ and $T_{2}=$ time in days. Food conversion ratio was calculated as FCR = food fed/live wt gain.

Eight weeks before placing the fish in the tanks, a fishless nitrogen cycle was commenced. Tanks were filled with city water (day -56), loaded filters were turned on, and residual chlorine gas was removed by aeration for $24 \mathrm{~h}$. Starting on day -56, tank water was inoculated weekly with Clear-FLO ${ }^{\circledR} 11001 x$ containing Nitrosomonas and Nitrobacter (Alken-Murray Corp.) according to the manufacturer's instructions. On day 
-36, one adult fish was placed in each tank and fed twice a day to increase ammonia levels and organic material. After the ammonia and nitrite levels peaked and subsided to near zero levels, the first fish was removed and the 10 trial fish were added. Tanks were topped-up once every two weeks with city water (approx $10 \mathrm{I}$ ) due to water loss from evaporation. After fish were introduced to the tanks, sodium bicarbonate was added daily ( $25 \%$ of the weight of the provided feed) to each tank (except the controls) to maintain an appropriate $\mathrm{pH}$ level and stimulate bacterial growth in the biofilters.

Dissolved oxygen and temperature (Orion model 810, Orion Research Inc.) and pH (Crison, mod. 507) were measured three times a week throughout the trial. In addition, one water sample $(250 \mathrm{ml})$ was taken from each tank on days 0 and 49 to measure electrical conductivity (EC), bicarbonate $\left(\mathrm{HCO}_{3}{ }^{-}\right)$, nitrate $\left(\mathrm{NO}_{3}{ }^{-}\right)$, ammonium $\left(\mathrm{NH}_{4}{ }^{+}\right)$, phosphates $\left(\mathrm{H}_{2} \mathrm{PO}_{4}^{-}\right)$, sulfates $\left(\mathrm{SO}_{4}{ }^{2-}\right)$, chloride $\left(\mathrm{Cl}^{-}\right)$, sodium $\left(\mathrm{Na}^{+}\right)$, potassium $\left(\mathrm{K}^{+}\right)$, calcium $\left(\mathrm{Ca}^{2+}\right)$, and magnesium $\left(\mathrm{Mg}^{2+}\right)$. EC and bicarbonates were measured with a 716Titrino DMS, sample exchanger 730, automatic arm 759, and conductivimeter 712. For the rest of the measurements, ion chromatography (Compact IC 761 and IC Sample Processor 766 linked to a computer) was used. Before analysis, samples were passed through a $0.45 \mu \mathrm{m}$ pore filter. Using data from the ion analysis, we calculated carbon dioxide $\left(\mathrm{CO}_{2}\right)$ and ammonium $\left(\mathrm{NH}_{4}{ }^{+}\right)$levels as per Timmons et al. (2002).

At the end of the experiment (day 49), three fish per treatment were removed for body composition analysis and frozen at $-80^{\circ} \mathrm{C}$. Several weeks later the samples were thawed, blended, lyophilized for $72 \mathrm{~h}$, and analyzed according to procedures outlined by AOAC International (2000) for dry matter (oven drying method 930.15), ash (muffle furnace incineration 923.03), crude protein (Dumas method 968.06; FP-528 LECO ${ }^{2}$, St. Joseph, MI), and ether extract (Soxhlet fat analysis 920.39).

On the last day of the experiment (day 49), blood samples were taken from two fish from each tank to determine plasma cortisol levels. Fish were caught and placed in a bucket with tank water and an anesthetic (tricaine methasulfonate; Orgamol, S.A., 1 $\mathrm{g} / 10 \mathrm{l}$ ). Once anesthetized, $0.5 \mathrm{ml}$ blood was withdrawn from the caudal vein using 1-m syringes (BD Plastipak) with heparin (1000 IU/ml; Chiesi España S.A.). Care was taken to carry out the blood sampling in less than $5 \mathrm{~min}$ to decrease the possible effects of sampling on the cortisol level. Samples were centrifuged at $1500 \times g$ for $5 \mathrm{~min}$ and plasma was extracted and kept at $-80^{\circ} \mathrm{C}$ until competitive radio-immuno analysis following Yalow and Berson (1971) with I-125 (DSL Cortisol RIA kit, DSL-2000, Diagnostic Systems Laboratories, Inc.).

The experimental protocol was approved by the Animal Experimentation Ethics Committee of the Polytechnic University of Madrid.

Data on growth, water quality, body composition, and plasma cortisol were analyzed using the Proc Mixed procedure of the SAS statistical package (SAS, 2002) with feeding interval as the fixed effect, biological filter as a random effect, and initial weight as a covariate. The Repeated Measures procedure was used to analyze oxygen, $\mathrm{pH}$, and temperature data. Means were compared using the LSD test with $p<0.05$ as the level of significance.

\section{Results}

There were no significant differences in initial or final live weight (Table 1). Weight gain was significantly higher in fish fed four times every day than in fish that fasted every fourth day. Fish fed every day had a significantly higher feed intake than those that fasted. As a result, despite the difference in weight gain, FCR and SGR were similar among treatments (Fig. 1).

Plasma cortisol levels varied more than growth parameters but did not significantly differ among treatments. Percent dry matter was highest and percent ash lowest in fish that were fed twice a day and fasted every fourth day, but protein was approximately $2 \%$ higher in fish fed four times a day and fasted. Accumulated fat content (ether extract) was quite low in those fed twice every day. Dissolved $\mathrm{O}_{2}$ and $\mathrm{pH}$ tended to be higher in tanks containing fish that fasted. Electrical conductivity, $\mathrm{Na}^{+}$, and $\mathrm{Cl}^{-}$were significantly highest in tanks that contained fish fed twice a day and fasted every fourth. 
Table 1. Growth, carcass composition, and water quality in Nile tilapia juveniles fed 49 days at different feeding frequencies.

\begin{tabular}{|c|c|c|c|c|c|c|}
\hline & \multicolumn{2}{|c|}{$\begin{array}{l}\text { No fast days } \\
\text { (feedings/d) }\end{array}$} & \multicolumn{2}{|c|}{$\begin{array}{c}\text { Fast every } \\
\text { fourth day } \\
\text { (feedings/d) }\end{array}$} & \multirow[b]{2}{*}{ SEM } & \multirow[b]{2}{*}{$p$} \\
\hline & 2 & 4 & 2 & 4 & & \\
\hline Initial wt (g) & 22.1 & 28.7 & 21.7 & 24.8 & 1.99 & 0.22 \\
\hline Final wt $(\mathrm{g})$ & 54.3 & 66.2 & 50.0 & 51.2 & 1.69 & 0.07 \\
\hline Wt gain $(\mathrm{g})$ & $32.2^{\mathrm{ab}}$ & $37.5^{\mathrm{a}}$ & $28.3^{b}$ & $26.4^{\mathrm{b}}$ & 0.55 & 0.03 \\
\hline Intake ( $\mathrm{g} /$ fish) & $43.3^{a}$ & $43.5^{a}$ & $32.2^{b}$ & $32.7^{b}$ & 0.27 & $<0.00$ \\
\hline FCR $(g / g)$ & 1.75 & 1.60 & 1.62 & 1.39 & 0.10 & 0.21 \\
\hline SGR $(\% / d)$ & 1.32 & 1.17 & 1.17 & 1.24 & 0.02 & 0.29 \\
\hline Cortisol $(\mathrm{ng} / \mathrm{ml})$ & 79.9 & 15.4 & 24.6 & 30.1 & 9.03 & 0.34 \\
\hline \multicolumn{7}{|c|}{ Carcass composition (\%) } \\
\hline Dry matter & $24.9^{\mathrm{ab}}$ & $24.7^{b}$ & $26.7^{\mathrm{a}}$ & $25.2^{\mathrm{ab}}$ & 0.44 & 0.038 \\
\hline Ash & $17.5^{\mathrm{a}}$ & $17.5^{\mathrm{a}}$ & $15.6^{\mathrm{b}}$ & $17.5^{\mathrm{a}}$ & 0.14 & $<0.00$ \\
\hline Protein & $61.3^{b}$ & $61.4^{b}$ & $61.5^{b}$ & $63.7^{\mathrm{a}}$ & 0.44 & 0.013 \\
\hline Lipid & $9.1^{\mathrm{c}}$ & $19.9^{\mathrm{a}}$ & $13.9^{b}$ & $18.8^{\mathrm{a}}$ & 0.82 & $<0.00$ \\
\hline \multicolumn{7}{|l|}{ Water quality* } \\
\hline $\mathrm{O}_{2}$ & 4.98 & 4.99 & 5.44 & 5.68 & 0.07 & 0.09 \\
\hline $\mathrm{pH}$ & 6.33 & 6.12 & 6.62 & 6.75 & 0.04 & 0.10 \\
\hline EC & $1.03^{\mathrm{b}}$ & $0.83^{b}$ & $1.30^{\mathrm{a}}$ & $0.90^{\mathrm{b}}$ & 0.08 & 0.014 \\
\hline $\mathrm{HCO}_{3}^{-}$ & 19.5 & 9.2 & 12.0 & 8.2 & 6.06 & 0.57 \\
\hline $\mathrm{NO}_{3}^{-}$ & 340.7 & 294.4 & 332.1 & 296.7 & 38.2 & 0.76 \\
\hline $\mathrm{H}_{2} \mathrm{PO}_{4}^{-}$ & 11.9 & 8.4 & 8.5 & 8.6 & 2.6 & 0.74 \\
\hline $\mathrm{SO}_{4}^{-}$ & 11.4 & 9.1 & 11.7 & 9.6 & 1.1 & 0.30 \\
\hline $\mathrm{Na}^{+}$ & $205.7^{\mathrm{b}}$ & $172.0^{\mathrm{b}}$ & $264.4^{\mathrm{a}}$ & $184.0^{\mathrm{b}}$ & 13.0 & 0.005 \\
\hline $\mathrm{Cl}^{-} \mathrm{rar}$ & $89.0^{\mathrm{b}}$ & $79.2^{b}$ & $176.4^{\mathrm{a}}$ & $93.6^{\mathrm{b}}$ & 14.4 & 0.005 \\
\hline $\mathrm{K}^{+}$ & 16.3 & 14.5 & 15.1 & 15.6 & 1.4 & 0.81 \\
\hline $\mathrm{Ca}^{2+}$ & 16.8 & 10.9 & 16.5 & 12.4 & 2.4 & 0.29 \\
\hline $\mathrm{Mg}^{2+}$ & 4.3 & 3.5 & 3.8 & 3.7 & 0.3 & 0.25 \\
\hline
\end{tabular}

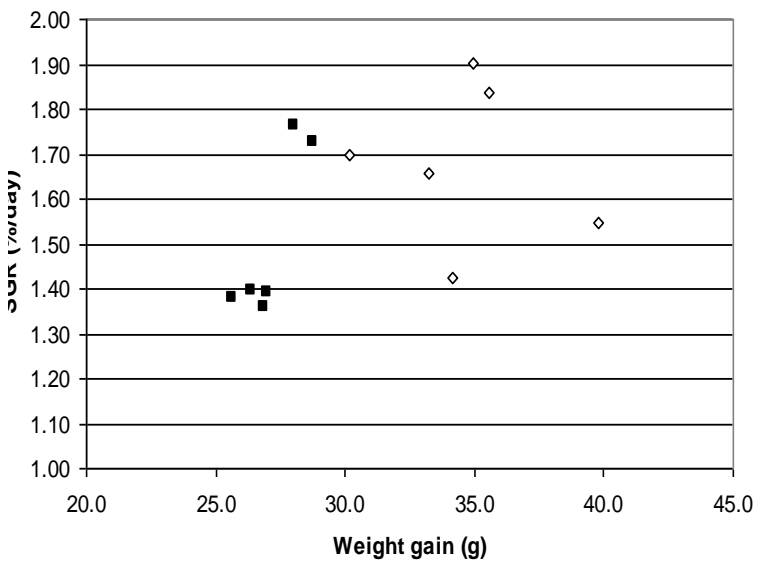

Fig. 1. Relationship between specific growth rate and weight fed daily $(\diamond)$ or fed for three days then fasted for one ( $\mathbf{a})$.

\section{Discussion}

Tilapia fed four meals every day obtained the best growth, suggesting that a feeding interval of $4 \mathrm{~h}$ between meals well corresponds with gastric evacuation times in this species and improves digestibility, in agreement with Riche et al. (2004a). Nonetheless, growth did not significantly differ when the feeding interval was increased to $12 \mathrm{~h}$ between meals, i.e., two meals a day. However, cortisol levels tended to be higher in fish fed only twice every day, suggesting that increasing the feeding interval may increase the stress level and decrease welfare. Fish that fasted received less feed and underwent larger relative changes in the feeding interval; this decreased growth but improved some aspects of water quality without increasing plasma cortisol.

Fish that were fed twice a day and fasted had a 12-h feeding interval for three days, then a 36-h fast from 20:00 on the third day until 08:00 on the first day of the next feeding cycle. These fish underwent a relative change in feeding interval from 12 o $36 \mathrm{~h}$. Similarly, fish fed four times a day had a 4-h feeding interval for three days, and then a 36-h fast from 20:00 on the third day until 08:00 on the first day of the next feeding cycle. In these fish, the relative change was from 4 to $36 \mathrm{~h}$. However, both groups had similar growth rates, suggesting that tilapia can adjust well to relatively large shifts in feeding interval.

Fish that fasted one day a week gained less weight than those fed every day, most probably because they received less food overall. However, SGR was similar among all treatments, suggesting that restricted feeding is feasible and has little effect on growth, while being more cost efficient (approximately $25 \%$ less feed was consumed). Similarly, tilapia that fasted for two days after five consecutive days of being fed three times a day grew less than those fed every day (Byamungu et al., 2001). However, while feed efficiency in fish may increase after restricted feeding ( $\mathrm{Li}$ et al., 2005), some studies found little effect (Wang et al., 2000).

In our study there were little differences in FCR between treatments, supporting the hypothesis that feeding frequency may have little effect on FCR and that food consumption is a main limiting factor for growth (Wang et al., 1998). There were no differences in growth among juvenile Nile tilapia $(34 \mathrm{~g}$ ) fed two, four, or five times/day (Riche et al., 2004b). The suggested optimum feeding interval is $4 \mathrm{~h}$ for Nile tilapia of 
$183 \mathrm{~g}$ (Riche et al., 2004a) while a continuous food supply instead of two meals/day is suggested for hybrid tilapia of $0.56 \mathrm{~g}$ (Lin et al., 1997).

Reduced or negative growth is commonly observed under conditions of stress, and cortisol is known to inhibit somatic growth by stimulating energy consumption, gluconeogenesis, and lipolysis in several teleost species (Wendelaar-Bonga, 1997). When fasting, a central component of stress adaptation seems to be the reallocation of metabolic energy from growth and reproduction to activities that restore homeostasis, such as respiration, locomotion, and hydromineral balance (Uchida et al., 2003).

Although tilapia is one of the most cultivated groups of fish, few studies have considered the effect of fasting or feeding frequency on plasma cortisol, although some have determined other hormones (Fox et al., 2006). There were no differences in plasma cortisol values $(300-400 \mathrm{ng} / \mathrm{ml})$ between continuously-fed tilapia and tilapia that fasted for two weeks (Uchida et al., 2003). The resting levels of cortisol for tilapia are approximately $20 \mathrm{ng} / \mathrm{ml}$ (Foo and Lam, 1993; Balm et al., 1994), very similar to those obtained in the present experiment. Thus it can be concluded that, despite the high variability even within treatments, the feeding frequencies used here did not excessively stress the tilapia. On the other hand, however, the successful adaptation of Nile tilapia to chronic stress makes it difficult to diagnose stress by measuring plasma cortisol alone since cortisol returns to its basal or pre-stress level several weeks after the beginning of stress. In some cases, plasma cortisol levels remain within basal values in spite of stress (Barcellos et al., 1999; Fast et al., 2008). Further experiments are needed to increase our knowledge about the role of cortisol on feeding strategies.

Regarding body composition, our results suggest more differences between frequencies (two or four times a day) than between continuously-fed and fasted fish, i.e., there was more fat in fish fed four times a day, with or without fasting, than in fish fed twice a day. Likewise, protein and ash were lower (but lipid higher) in tilapia fed three times a day, as compared to once, twice, or five times a day (Riche et al., 2004a).

EC, $\mathrm{Na}^{+}$, and $\mathrm{Cl}^{-}$were significantly highest in fish fed twice a day and fasted. All other water quality parameters were similar among treatments. There is little information in the literature on the effect of feeding frequency on dissolved ions in closed recirculation systems, but the increases in dissolved ions in low and high accumulation recirculation systems have recently been compared (Martins et al., 2009). In most cases, the accumulation of ions in their system was higher than in our study (e.g., $\mathrm{Ca}^{2+} 45-75 \mathrm{ppm}$, $\mathrm{K}^{+}$6-112 ppm, $\mathrm{Mg}^{2+}$ 7-20 ppm) but their sodium levels were much lower (23-56 ppm), probably because we used sodium bicarbonate to control $\mathrm{pH}$. However, since the same amount was added to each tank, this cannot explain the higher $\mathrm{Na}^{+}$and $\mathrm{Cl}^{-}$values in the twice a day/fasting treatment. Interestingly, these fish also had a significantly lower percentage of ash in their body composition, again underlying a possible ion imbalance in fish fasted for one day and fed twice a day.

In conclusion, tilapia subjected to skip-a-day feeding grew less than fish that were not fasted, most probably due to the lower overall amount of feed they received. Feed efficiency was similar for all treatments, suggesting that short term fasting can be used to decrease feeding costs with little effect on body composition. Water quality values were well within acceptable limits for tilapia growth, but the higher $\mathrm{EC}, \mathrm{Na}+$, and $\mathrm{Cl}$ - in the twice a day/fasting treatment indicate a possible risk of ion imbalance.

\section{Acknowledgements}

We wish to thank R. Barrera from Valenciana de Acuicultura (Pujol, Valencia) for supplying the fish and technical help. We also acknowledge E. Revuelta and F. Berdejo for their help in carrying out the trial and J.M. Durán and O. Ramos for the water analyses. This study was financed by the Spanish Ministry of Science and Education (Project AGL2005-07571-C02).

\section{References}

AOAC, 2000. Official Methods of Analysis of AOAC International, 16th ed. Assoc. Analytical Communities Int., Arlington, VA. 
Balm P.H.M., Pepels P., Helfrich S., Hovens M.L.H. and S.E. Wendelaar-Bonga, 1994. Adrenocorticotropic hormone in relation to interrenal function during stress in tilapia (Oreochromis mossambicus). Gen. Comp. Endocrinol., 96:347-360.

Barcellos L.J.G., Nicolalewsky S., de Souza S.M.G. and F. Luhlier, 1999. Plasmatic levels of cortisol in the response to acute stress in Nile tilapia, Oreochromis niloticus (L.), previously exposed to chronic stress. Aquacult. Res., 30:437-444.

Byamungu N., Darras V.M. and E.R. Kühn, 2001. Growth of heat-shock induced triploids of blue tilapia, Oreochromis aureus, reared in tanks and in ponds in Eastern Congo: feeding regimes and compensatory growth response of triploid females. Aquaculture, 198:109-122.

Fast M.D., Hosoya S., Johnson S.C. and L.O.B. Afonso, 2008. Cortisol response and immune-related effects of Atlantic salmon (Salmo salar Linnaeus) subjected to short- and long-term stress. Fish Shellfish Immunol., 24:194-204.

Foo J.T.W. and T.J. Lam, 1993. Serum cortisol response to handling stress and the effect of cortisol implantation on testosterone levels in the tilapia, Oreochromis mossambicus. Aquaculture, 115:145-148.

Fox B.K., Riley L.G., Hirano T. and E.G. Grau, 2006. Effects of fasting on growth hormone, growth hormone receptor, and insulin-like growth factor-I axis in seawateracclimated tilapia, Oreochromis mossambicus. Gen. Comp. Endocrinol., 148:340-347.

Garcia J.A. and M. Villarroel, 2009. Effect of feed type and feeding frequency on macrophage functions in tilapia (Oreochromis niloticus L.). Fish Shellfish Immunol., 27:325-329.

Li M.H., Robinson E.H. and B.G. Bosworth, 2005. Effects of periodic feed deprivation on growth, feed efficiency, processing yield and body composition of channel catfish Ictalurus punctatus. J. World Aquacult. Soc., 36:444-453.

Lin J.H., Cui Y., Hung S. and S.Y. Shiau, 1997. Effect of feeding strategy and carbohydrate source on carbohydrate utilization by white sturgeon (Acipenser transmontanus) and hybrid tilapia (Oreochromis niloticus x O. aureus). Aquaculture, 148:201-211.

Martins C.I.M., Pistrin M.G., Ende S.S.W., Eding E.H. and J.A.J. Verte, 2009. The accumulation of substances in recirculating aquaculture systems (RAS) affects embryonic and larval development in common carp Cyprinus carpio. Aquaculture, 291:65-73.

Oyedeji J.O. and J.O. Atteh, 2005. Response of broilers to feeding manipulations. Int. J. Poult. Sci., 4:91-95.

Riche M., Oetker M., Haley D.I., Smith T. and D.L. Garling, 2004a. Effect of feeding frequency on consumption, growth, and efficiency in juvenile tilapia (Oreochromis niloticus). Isr. J. Aquacult. - Bamidgeh, 56:247-255.

Riche M., Haley D.I., Oetker M., Garbrecht S. and D.L. Garling, 2004b. Effect of feeding frequency on gastric evacuation and the return of appetite in tilapia Oreochromis niloticus (L). Aquaculture, 234:657-673.

Timmons M.B., Ebeling J.M., Wheaton F.W., Summerfelt S.T. and B.J. Vinci, 2002. Water quality. pp. 19-50. In: Recirculating Aquaculture Systems. Northeastern Regional Aquaculture Center, USDA. Cayuga Aqua Ventures, Ithaca, NY.

Uchida K., Kajimura S., Riley L.G., Hirano T., Aida K. and E.G. Grau, 2003. Effects of fasting on growth hormone/insulin-like growth factor I axis in the tilapia, Oreochromis mossambicus. Comp. Biochem. Physiol. A, 134:429-439.

Wang N., Hayward R.S. and D.B. Noltie, 1998. Effect of feeding frequency on food consumption, growth, size variation, and feeding pattern of age-0 hybrid sunfish. Aquaculture, 165:261-267.

Wang Y., Cui Y., Yang Y. and C. Fasheng, 2000. Compensatory growth in hybrid tilapia, Oreochromis mossambicus $\times 0$. niloticus, reared in seawater. Aquaculture, 189:101-108.

Wendelaar-Bonga S.E., 1997. The stress response in fish. Physiol. Rev., 77:591-625.

Yalow R.S. and S.A. Berson, 1971. Further studies on the nature of immunoreactive gastrin in human plasma. Gastroenterology, 60:203-214. 